\title{
Enthusiastic caution
}

\section{How often have we convinced ourselves of} the necessity to attend that attractive postgraduate course on endodontics or implants (especially when it is held in some exotic location)?

\section{n the leader in the last issue (October 9, 1999) I described the dangers of allowing the enthusiasm of others to blind us to a more reasoned, careful and logical approach to matters, especially when those matters involve the treatment and care of patients. This leader is the companion to that, because it looks at the other side of the coin of the potential danger of enthusiasm - when we use it unknowingly on ourselves.}

Enthusiastic caution is my terminology for the awareness that we often rationalise our thoughts to excuse our behaviour. Our enthusiasm for a particular approach or idea overrides our basic awareness that we should stand back and take a more reasoned view.

The key word in the above paragraph is 'rationalise'. We all know the sort of thing. We see the bargain of the century in a shop or advertised in a magazine. We know we do not need one, but it would be a shame to miss out on the savings so we rationalise a reason for buying it now (in other words we find an excuse to justify the purchase) and then we buy it. Who among us has not done this at some time or other?

We do the same in dentistry. How many dentists have cupboards full of gadgets that seemed ideal at the time but have lain unused ever since? How many have ordered the bulk order to get that smart free flight bag (despite the fact we have half a dozen flight bags in the wardrobe at home)? How often have we convinced ourselves of the necessity to attend that attractive postgraduate course on endodontics or implants (especially when it is held in some exotic location)?

The last example is an ideal one because it not only challenges one of the most observed patterns of professional behaviour, but also illustrates exactly what I mean by enthusiastic caution.

Everyone accepts the idea that training is an essential part of continuing development, both for individuals and for organisations (or businesses). Commonsense would suggest that we should make that training effective. In other words, people should use training as a way of becoming more proficient and confident at doing what they need to do in order to achieve the objectives of the organisation or business. Thus the first stage is to identify the objectives of the business, then the training needs of the people involved.

That is the theory. The reality is that most training in professional practice (not just dentistry) tends to be focused on subject areas that individuals enjoy and are often very competent in already. The business objectives set by the practice may well be an increase in profitability and in the number of patients that are attracted to the practice, but instead of learning about both finance and marketing we find the dentists attending courses on implants. If challenged, the response is that they need to know whether implants can attract new patients and increase profits, but that is a superb piece of enthusiastic caution. Surely the more appropriate approach is to understand the principles of financial management and marketing first, which may well identify far more effective ways of achieving the objectives than offering implants?

As I stated at the st art of these two leaders there is a danger of allowing enthusiasm (either in others or in ourselves) to blind us to the most appropriate behaviour, especially when considering changes in our clinical philosophy and behaviour. We have a duty and responsibility to be both ethical and responsible because inappropriate behaviour can have a devastating effect on our patients. We also need to respond to enthusiasm and remain enthusiastic ourselves, for the sake of our own development and for the benefit of those we care for and work with. It is simply a matter of balance. 